\title{
Differential sensitivity of hormone-responsive and unresponsive human prostate cancer cells (LNCaP) to tumor necrosis factor*
}

\author{
X. Zhao, G. J. van Steenbrugge, and F. H. Schröder \\ Department of Urology, Erasmus University, Rotterdam, The Netherlands
}

Accepted: September 3, 1991

Summary. Two sublines, the hormone-sensitive LNCaPFGC and the insensitive LNCaP-r (resistant) carcinoma cell lines, originating from the parental human prostatic carcinoma cell line $\mathrm{LNCaP}$ were tested for sensitivity to human tumor necrosis factor- $\alpha$ (TNF) using the MTT assay. Irrespective of the culture conditions, i.e., whether FGC cell growth was hormone stimulated or hormone deprived, a clear dose-related response was observed between the concentration of TNF (range: $5-5000 \mathrm{U} / \mathrm{ml}$ ) in the culture medium and the percentage of growth inhibition. In medium containing androgen-depleted serum, in which FGC cells showed reduced proliferative activity, the percentage of inhibition by a concentration of $100 \mathrm{U} / \mathrm{ml}$ TNF was substantially higher than that found in hormone-stimulated cells ( $90 \%$ and $60 \%$, respectively). In contrast to the FGC cells, the hormone-insensitive LNCaP-r cells were almost completely resistant to the action of TNF. Growth of the FGC cells was almost completely inhibited, whereas growth of the LNCaP-r cells was retarded with only $20 \%$ at dosages up to 5000 $\mathrm{U} / \mathrm{ml}$. This substantial difference in TNF responsiveness could not be ascribed to differences in TNF-binding capacity, as both the FGC and LNCaP-r cells were found to contain identical numbers of TNF-receptors (approximately 1000 sites/cell). A possible association between hormone responsiveness and TNF sensitivity is suggested for these $\mathrm{LNCaP}$ sublines.

Key words: Prostate cancer - LNCaP cell line - Tumor necrosis factor - Hormone sensitivity

Ever since Huggins' and Hodges' report on the androgen dependence of prostate carcinoma, androgen ablation therapy has remained the treatment of choice for ad-

\footnotetext{
* This study was supported in part by the Stichting Urologisch Wetenschappelijk Onderzoek (SUWO)

This paper was selected for publication in Urological Research from the program of the 1991 meeting of the European Society of Urological Oncology and Endocrinology (ESUOE)
}

vanced prostate neoplasia $[17,31]$. Most patients with advanced prostate cancer can be symptomatically improved by anti-androgen therapy. This approach is not curative, however, and the patient will ultimately succumb to the progression of disease unresponsive to hormones [18] and resistant to current therapeutic modalities. As a result, prostate cancer continues to be the second cause of death from cancer in men [28].

Significant improvements in the efficacy of experimental cancer therapies have been made by utilization of biological response modifiers [1-3]. TNF is a wellcharacterized secretory product of macrophages, which has shown direct antitumor activity in vivo as well as in vitro [11, 12]. The potential of immunotherapy, specifically with TNF, in the treatment of advanced prostate cancer has received limited attention.

Among the small number of permanent in vitro cell lines of human prostate cancer described up to now, the $\mathrm{LNCaP}$ (lymph node carcinoma of the prostate) cell line, developed by Horoszewicz [15], is the only model with androgen-responsive growth [16]. LNCaP cells secrete prostatic acid phosphatase and prostate-specific antigen; the cells also contain considerable amounts of androgen receptors [4] and have been shown to secrete polypeptide growth factors, such as epidermal growth factor (EGF) and transforming growth factor- $\alpha$ [8]. Propagation of $\mathrm{LNCaP}$ cell cultures has led to the development of a number of sublines with different patterns of hormone responsiveness. These sublines descended from the parental LNCaP line either spontaneously or by maintenance of the original cell line in medium with steroid-depleted serum. An example is the spontaneous androgen-insensitive LNCaP-r (resistant) subline, which has been developed and further characterized by Hasenson et al. [13].

The efficacy of TNF in the therapy of experimental prostatic carcinomas, including the LNCaP cell line, has been reported by some investigators $[10,23,27]$. In the present study, the anti-proliferative activity of human TNF was determined in untreated and in hormonedeprived, androgen-responsive and unresponsive sublines of the LNCaP model. 


\section{Materials and methods}

\section{Cell lines}

The LNCaP cell line was derived from culture explants of needle biopsy material from a lymph-node metastasis of a prostate cancer patient [15]. The LNCaP-FGC cell line descended from a fastgrowing colony of the original LNCaP cultures [29]. This line was kindly made available to us by Dr. Horoszewicz (Buffalo, N. Y. USA) and was transferred to our laboratory as a 16th-passage culture. Another subline of LNCaP, designated LNCaP-r, was kindly provided by Dr. Hasenson (Huddinge, Sweden). LNCaPFGC cells cultured in our laboratory for longer periods of time (5 months) in androgen-depleted medium (see next paragraph) are designated FGC-DCC [30].

\section{Cell culture}

Both the LNCaP-FGC and LNCaP-r lines were routinely maintained as monolayer cultures in RPMI 1640 medium (Gibco, Life Technologies Ltd., Paisly; U.K.) supplemented with $5 \%$ fetal bovine serum (FBS; Hyclone, Greiner, Alphen a/d Rijn, The Netherlands), $2 \mathrm{mM} L$-glutamine, $100 \mathrm{units} / \mathrm{ml}$ penicillin and $100 \mu \mathrm{g} / \mathrm{ml}$ streptomycin. LNCaP-FGC cells were also grown for longer periods of time (up to 5 months) in medium containing $5 \%$ dextran-coated charcoal (DCC; dextran $0.1 \%$, charcoal $1 \%$ ) treated (i.e., steroid-depleted) serum. Untreated (FBS) serum contained $0.5-1.0 \mathrm{nM}$ of testosterone (T), whereas in DCC serum less than $0.1 \mathrm{nM}$ of $\mathrm{T}$ (the detection limit of the assay) was estimated. All cultures were grown in $25 \mathrm{~cm}^{2}$ plastic tissue culture flasks (Falcon, Oxnard, Calif.) and kept in a $5 \% \mathrm{CO}_{2}-$ humidified air incubator at $37^{\circ} \mathrm{C}$. Cells were subcultivated at weekly intervals using a mixture of $0.05 \%$ trypsin and $0.02 \%$ EDTA.

\section{Tumor necrosis factor}

Recombinant human TNF- $\alpha$ was kindly provided by BASF/Knoll $\mathrm{AG}$ (Ludwigshafen, FRG) and had a specific activity of $8.74 \times 10^{6}$ $\mathrm{U} / \mathrm{mg}$ protein, as measured on L929 cells in the absence of actinomycin D. TNF was dissolved in phosphate-buffered saline (PBS) plus $0.03 \%$ bovine serum albumin (BSA), aliquoted and stored at $-80^{\circ} \mathrm{C}$.

\section{Cell proliferation assay}

Evaluation of the effects of androgens or TNF on the growth of the LNCaP cells was performed using a test system based on the enzymatic reduction of the tetrazolium salt MTT [3-(4,5-dimethylthiazol-2-yl)-2,5-diphenyl-tetrazoliumbromide] [24]. This proliferation assay was previously described as being suitable for the assessment of hormone-stimulated growth of the LNCaP cell line [25]. Cells harvested from routine cultures were suspended in RPMI 1640 plus 5\% FBS and plated into 96-well flat-bottom microtiter plates (Costar, Cambride, Mass.) at a density of $5 \times 10^{3}$ cells/well in a volume of $0.1 \mathrm{ml}$. After plating and incubation of the cells for $24 \mathrm{~h}$ to allow for attachment (day 0), serial diluted TNF-containing media were added to the wells in the volume of $0.1 \mathrm{ml} /$ well to give a final concentration of TNF in the range of 5-5000 U/ml.

To determine the response of the LNCaP cells to androgens, cells were pretreated for 3 days in medium containing $5 \%$ DCC serum, after which the medium was replaced by either the same medium or medium containing FBS, with or without the addition of $0.1 \mathrm{nM}$ of the synthetic, non-metabolizable [6] androgen R 1881 (New England Nuclear, Boston, Mass.) to the respective media.
After exposing the cells to experimental media for 5 days, the cells were pulsed with MTT, incubated for $4 \mathrm{~h}$, the plates processed and the absorbance (OD) detected, as described by Romijn et al. [25]. Eight replicate wells were used for each experimental condition. The percentage of relative survival fraction was determined on the basis of day 0 using the formula: Relative survival fraction $=\left(O D_{\text {treated }}-\right.$ $\left.\mathrm{OD}_{\text {day } 0} / \mathrm{OD}_{\text {control }}-\mathrm{OD}_{\text {day } 0}\right) \times 100$.

\section{TNF receptor assay}

For TNF-binding studies, TNF was radiolabeled according to the method of Bolton and Hunter [5]. The number of TNF receptors was estimated as whole cells, using a ${ }^{125}$ I-TNF competitive ligand assay, as described by Budel et al. for IL-3 and GM-CSF [7].

\section{Statistics}

The significance of differences between values of different groups was calculated using the two-tailed Student's $t$-test.

\section{Results}

\section{Androgen responsiveness of $L N C a P$ cells}

It has previously been demonstrated that LNCaP-FGC cells can optimally be stimulated at a concentration of 0.1 nM R 1881, the levels reached being slightly lower than the cells grown in control (FBS) serum [30]. Figure 1 shows the result of an experiment in which the androgen responsiveness of the LNCaP-FGC line was compared to that of the LNCaP-r line. Over a period of 5 days, the growth of the FGC and $r$ cells was stimulated (3.2 and 4.5fold, respectively) when cultured in DCC medium. In contrast to the FGC cells, however, the LNCaP-r cells could not be significantly further stimulated by DCC medium with $\mathrm{R} 1881(0.1 \mathrm{nM})$, or by medium containing normal (FBS) serum (Fig. 1B). In fact, the LNCaP-r cells could be grown equally well in medium with DCC, DCC + R 1881, or FBS.

LNCaP-FGC cells that were continuously grown in DCC medium did not die, but their growth rate was clearly retarded. Such cultures could be maintained for long periods of time and, therefore, were considered a separate subline, designated FGC-DCC. Cells of this subline cultured for several months were still sensitive for androgens (i.e., R 1881) [30].

\section{Response of androgen-sensitive and insensitive cells to TNF}

Growth of androgen-sensitive LNCaP-FGC cells was significantly inhibited by TNF (Fig. 2). A clear doseresponse relationship was observed between the concentration of TNF $(5-5000 \mathrm{U} / \mathrm{ml})$ in the culture medium and the percentage of growth inhibition. Although there was some variation between the various experiments performed, the median TNF dose for the LNCaP-FGC cell was estimated at $50 \mathrm{U} / \mathrm{ml}$. In contrast, the $\mathrm{LNCaP}-\mathrm{r}$ line appeared to be highly resistant to TNF. At dosages of up 

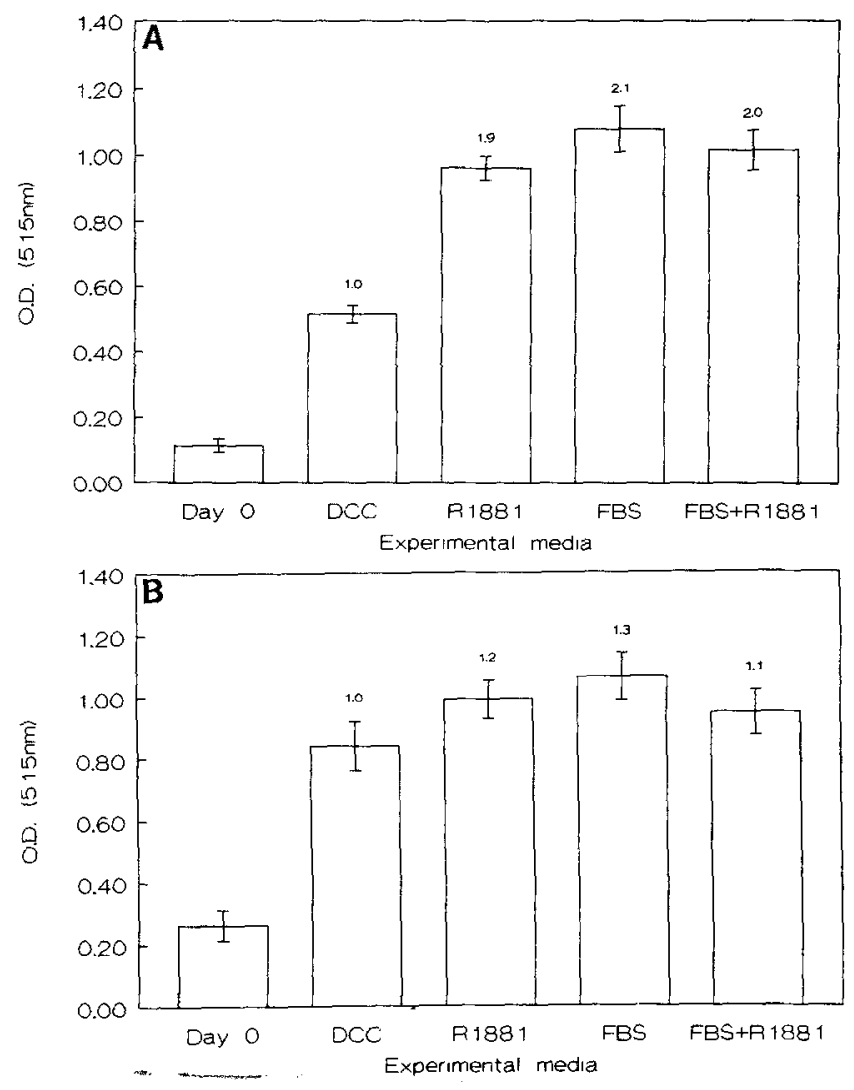

Fig. 1 A, B. Growth of LNCaP-FGC cells (A) and LNCaP-r cells (B) in complete (FBS) and androgen-depleted (DCC) medium with and without the synthetic androgen $\mathrm{R} 1881$. Values represent mean \pm SD; growth stimulation factor compared to DCC group is indicated at the top of each bar. Results were evaluated using MTT assay (for details, see Materials and methods section)

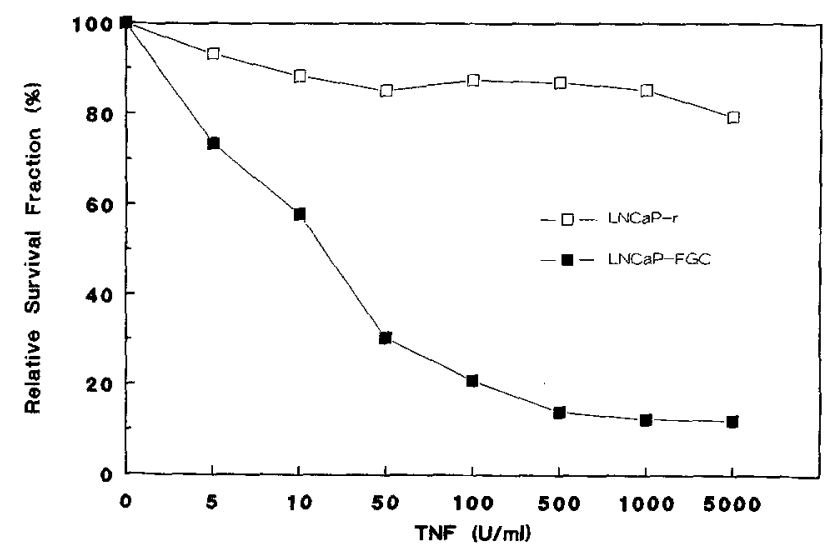

Fig. 2. Response of the LNCaP-FGC and LNCaP-r cells to various concentrations of human TNF- $\alpha$. Cells were grown in the presence of $5 \%$ FBS and exposed to TNF for 5 days

to $5000 \mathrm{U} / \mathrm{ml}$ of TNF, growth of the FGC cells was almost completely abolished, whereas growth of the LNCaP-r cells was inhibited by only $20 \%$ (Fig. 2). Both the LNCaPFGC and LNCaP-r cells contain identical numbers of TNF receptors, the concentration being estimated at 1000 sites/cell (data not shown).
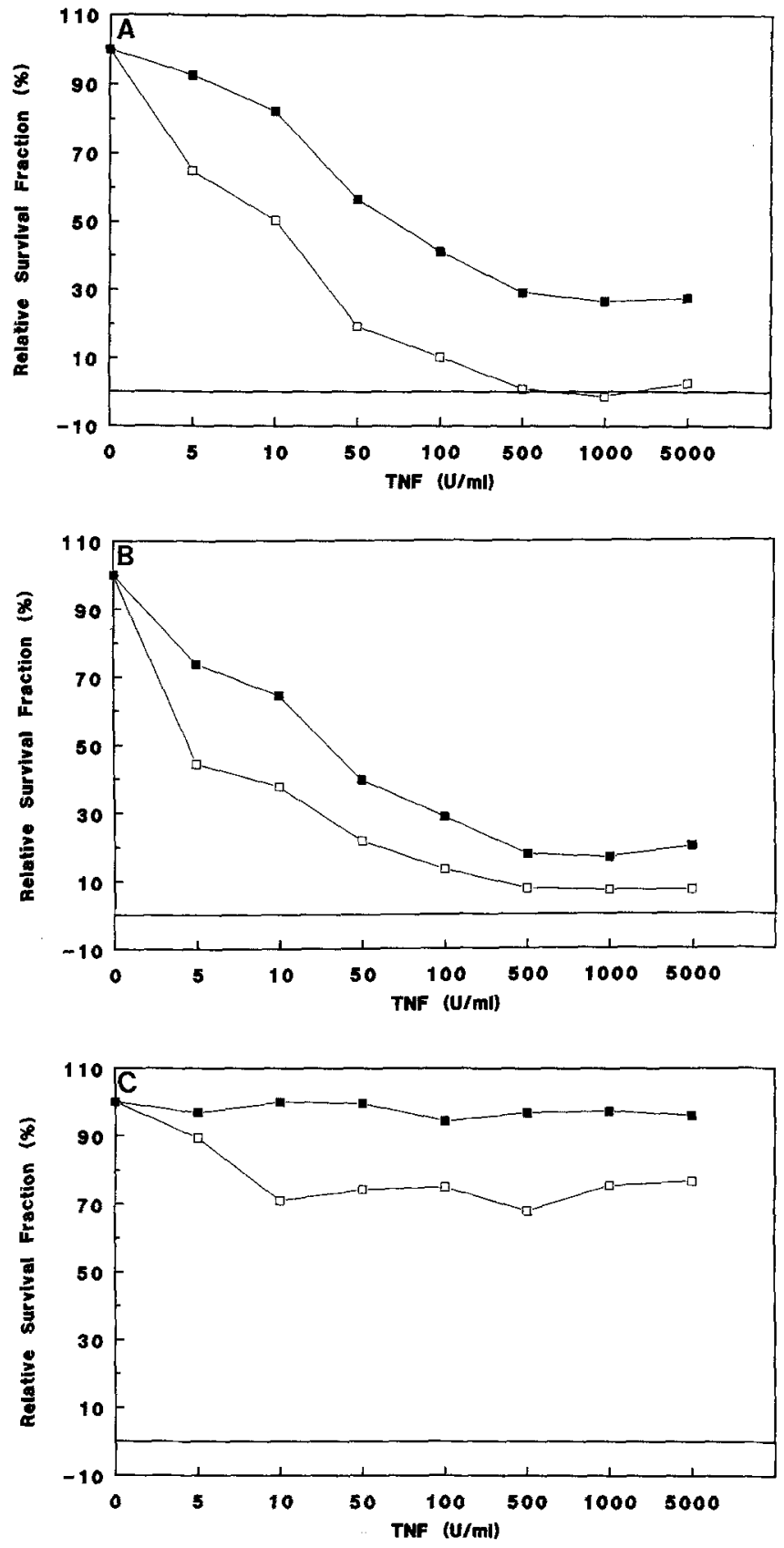

Fig. 3A-C. TNF responsiveness of LNCaP-FGC (A), FGC-DCC (B) and LNCaP-r (C) cells grown under the condition of steroiddepleted (DCC) medium ( $\square$ ) or DCC medium supplemented with $0.1 \mathrm{nM}$ R 1881 ( $)$

\section{Effect of androgen-depletion on TNF responsiveness}

Figure 3 shows the result of a TNF dose-response experiment with LNCaP-FGC, FGC-DCC and LNCaP-r cells either grown in DCC medium or in DCC medium with androgen (R 1881). LNCaP-FGC cells grown in androgen-depleted (DCC) medium showed reduced proliferative activity (Fig. 1) and appeared to be significantly $(P<0.001)$ more sensitive to TNF in comparison to cells stimulated with the androgen R1881 (Fig. 3A). When optimally grown LNCaP-FGC cells are stimulated by serum or by androgens, the response is apparently similar 
with either dose of TNF (cf. Figs. 2 and 3A). The TNF response pattern was found to be about the same with FGC-DCC cells, i.e., LNCaP-FGC cells that were deprived of androgens for several months (Fig. 3B). TNF treatment of LNCaP-r cells cultured in DCC medium resulted in a maximal inhibition of $25 \%$, which was comparable to the result obtained with cells grown in FBS medium (cf. Fig. 2), whereas R1881 induced a further resistance to TNF (Fig. 3C). Over the whole range of TNF used, a statistically $(P<0.001)$ significant difference in the percentage of inhibition was found between cells cultured in DCC medium and in medium with R 1881 (Fig. 3C).

\section{Discussion}

Human cancer of the prostate is a complex disease and the study of several aspects of this type of cancer can only be investigated by the use of appropriate animal and in vitro systems. In spite of the efforts of many investigators to establish in vitro cultures of prostate epithelium, only a limited number of continuously growing cell lines of human prostate carcinoma has been developed. TNF is a macrophage/monocyte secretory product that plays an important role in host-mediated antitumor defence and the pathophysiological response to sepsis and neoplasia. TNF is directly cytotoxic to numerous tumor cell lines in vitro, but in general normal cells are resistant to TNFmediated cytolysis [12].

In the present study it was demonstrated that $\mathrm{LNCaP}$ FGC cells are highly sensitive for the anti-proliferative effects of TNF (Fig. 2). This result has been demonstrated before by other investigators $[10,27]$, but in these studies the possibility of combining hormone treatment, i.e., androgen withdrawal, and TNF therapy was not considered. In a previous study on the LNCaP cell line in our laboratory, it was shown that the LNCaP-FGC subline, which shares all the properties of the parental LNCaP cell line, including its androgen responsiveness, can be grown at a slow growth rate in androgen-depleted medium [30]. Under the condition of androgen-deprived growth of the LNCaP-FGC line, the cells appeared to be more susceptible to the antitumor effects of TNF in comparison with optimally growing LNCaP cultures (Fig. $3 \mathrm{~A}$ ). In addition, it was observed that long-term cultures of LNCaP-FGC cells in androgen depleted medium, did not lead to major changes in either the androgen responsiveness, or the inhibitory effect of TNF (Fig. 3B). For ventral prostate cells of the rat and for prostate carcinoma cells, it has been shown that androgen deprivation induces apoptosis [21], and TNF is also described as triggering this process in various cell types such as lymphocytes [26]. It is tempting to speculate that in the androgen-responsive $\mathrm{LNCaP}$ cells, TNF and anti-androgenic (e.g., androgen withdrawal) treatment act synergistically in the induction of apoptosis in these cells. This possibility is currently being investigated.

The LNCaP-r line emerged directly from the parental LNCaP cell line, as in a cytogenetic study by König et al. it was clearly demonstrated that the LNCaP-r subline had the same basic karyotype in common with the original
LNCaP line, including some new, subline-specific marker chromosomes [20]. LNCaP-FGC and-r cells differ in their responsiveness to estramustine, a compound used for the treatment of prostate carcinoma [14, 19]. In contrast to LNCaP-FGC cells which were shown to be inhibited with $70 \%$ by TNF at a dose of $50 \mathrm{U} / \mathrm{ml}$, the LNCaP-r cells appeared to be highly resistant to TNF (Fig. 2). Growth of the androgen-unresponsive LNCaP-r cells was retarded with only $20 \%$ at dosages of up to $5000 \mathrm{U} / \mathrm{ml}$. This substantial difference in TNF responsiveness could not be ascribed to dissimilarities in TNF binding capacity, as both the LNCaP-FGC and $\mathrm{r}$ cells were found to contain identical numbers of TNF receptors. This strongly suggests that TNF responsiveness in the LNCaP cell line is expressed at a post-receptor level. This has also been demonstrated for other cell lines, such as the ME-180 cervical tumor cell line [9]. At the post-receptor level, i.e., intracellularly, several pathways are known to be involved [22] in TNF signal transduction, although many uncertainties remain in this respect. Major steps in the TNFmediated cytotoxicity cascade include G-protein-coupled activation of phospholipases, generation of free radicals, and damage to nuclear DNA by endonucleases. Ultimately, the cells undergo apoptosis (see above) and die.

Conflicting data have been reported on the response of the hormone-independent prostate cancer cell line, PC-3. In a study by Sherwood et al. [27], the LNCaP cell line and hormone-independent PC-3 and DU-145 prostate carcinoma lines have all been found to be sensitive for the antitumor effect of TNF, as confirmed for the PC-3 cell in a study of Liu et al. [23]. In contrast, Fruehauf et al. [10] found the PC-3 cell to be highly resistant to TNF, and in their study the sensitivity of the LNCaP cell line was also confirmed. Generally, the number of prostate cell lines with different patterns of hormone sensitivity is too limited to allow conclusions to be made on the possible association between androgen and TNF responsiveness. As far as the LNCaP model is concerned, however, the present results with the FGC and $r$ sublines suggest a possible association between hormone responsiveness and TNF sensitivity. Consequently, as far as the possible application of TNF to clinical prostate cancer is concerned, the results with in vitro $\mathrm{LNCaP}$ cell lines do not indicate that therapeutic intervention with this cytokine would be helpful in progressive, hormone-independent prostate carcinoma. The approach in which TNF is applied in combination with anti-androgen therapy in hormone-responsive prostate cancer seems in this respect more promising. More experimental studies are necessary with in vitro cell lines but, more importantly, with in vivo models, such as transplantable human prostatic carcinomas in athymic nude mice.

Acknowledgements. The authors wish to thank Dr. L. M. Budel for TNF receptor measurements.

\section{References}

1. Baisch H, Otto U, Klöppel G (1990) Antiproliferative and cytotoxic effects of single and combined treatment with tumor 
necrosis factor $\alpha$ and/or $\alpha$ interferon on a human renal cell carcinoma xenotransplanted into nu/nu mice: cell kinetic studies. Cancer Res 50:6389

2. Beniers AJMC, Peelen WP, Hendriks BT, Schalken JA, Romijn JC, Debruyne FMJ (1988) In vitro antiproliferative efficacy of interferon-alpha, -gamma and tumor necrosis factor on two human renal tumor xenografts. Urol Res 16:309

3. Beniers AJMC, Moorselaar RJA van, Peelen WP, Debruyne FMJ, Schalken JA (1991) Differential sensitivity of renal cell carcinoma xenografts towards therapy with interferon-alpha, interferon-gamma, tumor necrosis factor and their combinations. Urol Res 19:91

4. Berns EMJJ, Boer W de, Mulder M (1986) Androgen dependent growth regulation of and the release of specific protein(s) by the androgen receptor containing human prostate tumor cell line LNCaP. Prostate 9:247

5. Bolton AE, Hunter WM (1973) The labelling of proteins to high specific radioactivities by conjugation to a ${ }^{125}$ I-containing acylating agent: application to the radio-immunoassay. Biochem J 133:529

6. Bonne C, Raynaud JP (1976) Methyltrienolone, a specific ligand for cellular androgen receptors. Steroids $26: 227$

7. Budel LM, Touw IP, Delwel R, Clark.SC, Löwenberg B (1989) Interleukin-3 and granulocyte-monocyte colony-stimulating factor receptors on human acute myelocytic leukemia cells and relationship to the proliferative response. Blood 74:565

8. Connolly JM, Rose DP (1990) Production of epidermal growth factor and transforming growth factor- $\alpha$ by the androgenresponsive $\mathrm{LNCaP}$ human prostate cancer cell line. Prostate $16: 209$

9. Donato NJ, Vijjeswarapu D, Rosenblum MG (1991) Expression and rapid phosphorylation of EGF receptor correlate with TNFresponsiveness in human cervical carcinoma cells. Proc Am Assoc Cancer Res 32:56

10. Fruehauf JP, Myers CE, Sinha BK (1990) Synergistic activity of suramin with tumor necrosis factor $\alpha$ and doxorubincin on human prostate cancer cell lines. J Natl Cancer Inst 82:1206

11. Haranaka K, Satomi N (1981) Cytotoxic activity of human necrosis factor (TNF) on human cancer cells in vitro. Jpn J Exp Med 51:191

12. Haranaka K, Satomi N, Sakurai A (1984) Antitumor activity of murine tumor necrosis factor (TNF) against transplanted murine tumors and heterotransplanted human tumors in nude mice. Int J Cancer 34:263

13. Hasenson M, Hartley-Asp B, Kihlfors C, Lundin A, Gustafsson $\mathrm{J}-\AA$, Pousette $\AA$ (1985) Effect of hormones on growth and ATP content of a human prostatic carcinoma cell line, LNCaP-r. Prostate 7:183

14. Hasenson M, Lundh B, Hartley-Asp B, Pousette $\AA$ (1988) Growth inhibiting effect of estramustine on two prostatic carcinoma cell lines, LNCaP and LNCaP-r. Urol Res 16:357

15. Horoszewicz JS, Leong S, Chu T, Wajsman Z, Friedman M, Papsidero L, Kim U, Chiu L, Kakati S, Arya S, Sandberg A (1980) The LNCaP cell line - a new model for studies on human prostatic carcinoma. Prog Clin Biol Res 37:115

16. Horoszewicz JS, Leong S, Kawinski E, Karr J, Rosenthal H, Chu TM, Mirand EA, Murphy GP (1983) LNCaP model of human prostatic carcinoma. Cancer Res 43:1809
17. Huggins C, Hodges CV (1941) Studies on prostatic cancer. I. The effect of castration, of estrogen and of androgen injection on sérum phosphatases in metastatic carcinoma of the prostate. Cancer Res 1:293

18. Isaacs JT, Kyprianou N (1987) Development of androgenindependent tumor cells and their implantation for the treatment of prostatic cancer. Urol Res 15:133

19. Jönsson G, Högberg B, Nilsson T (1977) Treatment of advanced prostatic carcinoma with estramustine phosphate. Scand Urol Nephrol 11:231

20. König JJ, Kamst E, Hagemeijer A, Romijn JC, Horoszewicz J, Schröder FH (1989) Cytogenetic characterization of several androgen responsive and unresponsive sublines of the human prostatic carcinoma cell line LNCaP. Urol Res 17:79

21. Kyprianou N, Isaacs JT (1988) Activation of programmed cell death in the rat ventral prostate after castration. Endocrinology 122:552

22. Larrick JW, Wright SC (1990) Cytotoxic mechanism of tumor necrosis factor-a. FASEB J 4:3215

23. Liu S, Ewing MW, Anglard P, Trahan E, La Rocca RV, Myers CE, Linehan WM (1991) The effect of suramin, tumor necrosis factor and interferon- $\gamma$ on human prostate carcinoma. J Urol $145: 389$

24. Mosmann T (1983) Rapid colorimetric assay for cellular growth and survival: application to proliferation and cytotoxicity assays. J Immunol Methods 65:55

25. Romijn JC, Verkoelen CF, Schroeder FH (1988) Application of the MTT assay to human prostate cancer cell lines in vitro: establishment of test conditions and assessment of hormonestimulated growth and drug-induced cytostatic and cytotoxic effects. Prostate 12:99

26. Rubin BY, Smith LJ, Hellerman GR, Lunn RM, Richardson NK, Anderson SL (1988) A correlation between the anticellular and DNA fragmenting activities of tumor necrosis factor. Cancer Res 48:6006

27. Sherwood ER, Ford TR, Lee C, Kozlowski JM (1990) Therapeutic efficacy of recombinant tumor necrosis factor $\alpha$ in an experimental model of human prostatic carcinoma. J Biol Response Mod 9:44

28. Silverberg E, Lubera A (1989) Cancer statistics, 1989. CA 39:12

29. Steenbrugge GJ van, Groen M, Dongen JW van, Bolt J, Korput $\mathrm{H}$ van der, Trapman J, Hasenson M, Horoszewicz J (1989) The human prostatic carcinoma cell line $\mathrm{LNCaP}$ and its derivatives: an overview. Urol Res 17:71

30. Steenbrugge GJ van, Uffelen CJC van, Bolt J, Schröder FH (1991) The human prostatic cancer cell line $\mathrm{LNCaP}$ and its derived sublines: an in vitro model for the study of androgensensitivity. J Steroid Biochem Mol Biol 40:207

31. Walsh PC (1975) Physiologic basis for hormonal therapy in carcinoma of the prostate. Urol Clin North Am 2:125

X. Zhao, MD

Division of Urological Oncology

Department of Urology, Room Ee-1006

Erasmus University Rotterdam

P.O. Box 1738

3000 DR Rotterdam

The Netherlands 